\title{
Depth estimation of surface-opening crack in concrete beams using impact-echo and non-contact video-based methods
}

\author{
Yamin Sun ${ }^{*}$, Pingming Huang, Jufeng Su and Tao Wang
}

\begin{abstract}
Surface-opening crack is one of the main defects in concrete bridges, which results in degradation in the loadcarrying capacity of these structures. Thus, estimating the depth of such surface-opening crack is vital. This study presents impact-echo (IE) and non-contact video-based methods to estimate the surface-opening crack of concrete beams in the laboratory, and the results are compared with visual inspection. Results show that the IE method estimates a considerably larger crack depth than the non-contact video-based method and visual inspection. Although the difference between the depth measured by non-contact video-based method and visual inspection is small, the depth estimated by non-contact video-based method is slightly larger than that measured by visual inspection because it can identify the unrecognizable micro-crack by visual inspection. Moreover, when adopting the IE method, the depth of inclined crack is more overestimated than the vertical crack.
\end{abstract}

Keywords: Surface-opening crack, Crack depth, Impact-echo method, Non-contact video-based method, Vertical crack, Inclined crack

\section{Introduction}

Bridge engineering has considerably developed in the past few decades. However, most of the bridges constructed decades ago have experienced different levels of degradation after being subjected to long-term environment attacks and load effects. The USA spend approximately $\$ 10$ billion annually on the repair and maintenance of their existing bridges [1]. Surface-opening crack is one of the most common defects for concrete bridges; it reduces stiffness and allows aggressive media, such as water and chloride, to corrode the reinforced bars, thereby causing the loss in load-carrying capacity. Therefore, measuring the depth of surface-opening crack to realize appropriate maintenance schedule is of considerable importance.

Nondestructive and destructive methods are commonly adopted in assessing the service condition of bridges; between the two, destructive methods are often of low efficiency and poor economic effect because they may core, drill, or include load test on the bridge structure [2]. Nondestructive test methods offer bridge

\footnotetext{
* Correspondence: sunyamin@chd.edu.cn

School of Highway, Chang'an University, Xi'an, Shaanxi 710064, People's Republic of China
}

managers and engineers fast and efficient approaches for bridge inspection and assessment. These methods include audio-visual methods, stress wave methods, electromagnetic methods, and miscellaneous tests [3]. For surface-opening cracks, audio-visual methods are the most extensively adopted because they are rapid and inexpensive in inspecting structures. However, such methods cannot measure the depth of surface-opening cracks because they are used to identify the apparent and superficial problems while the depth of the surface-opening crack may be larger than the superficial profile of the crack. A stress wave method called impact-echo (IE) method has been proposed and frequently adopted by researchers to identify the defects in concrete structures. The IE method was first used to detect concrete flaws [4] and later widely applied to interpret the severity of delamination in bridge deck [5] and detect large voids [6] and corrosion damage [7]. However, research regarding the depth of surface-opening crack is limited. Only few scholars have conducted experiments on concrete beams and slabs to apply this method for determining the depth of surface-opening crack [8-12]. 
With technical innovation, non-contact measurement systems have been recently invented and adopted by some researchers for monitoring the service condition of structures. Non-contact measurement systems mainly utilize laser, radar, and GPS technologies and images obtained via video technology and digital photography [13]. Among these technologies, video-based technology offers a way for researchers and engineers to access structure information considering multiple sections in a remote distance but with high resolution. Moreover, this method does not need to access the critical areas of structures when these areas are untouchable. In view of this, several researchers [13-17] have applied non-contact video-based measurement to field tests and verified the accuracy of this method by comparison with other conventional measurements. However, in the current literature, the use of non-contact video-based methods mainly focuses on the structure displacement, thereby ignoring the strain of the structure.

In this study, several concrete beams are loaded in the laboratory to generate surface-opening cracks. During the loading procedure, the non-contact videobased method combined with visual inspection is adopted to monitor the occurrence of crack. The crack tip is identified when the strain of the concrete exceeds the cracking strain. The crack depth is then estimated by measuring the distance between the tip and the surface of the crack. Meanwhile, the IE method is utilized to estimate the depth of such cracks using the time-of-flight (TOF) technique. Finally, the different methods are compared.

\section{Method}

When the IE method is applied, a transient mechanical impact is generated by a hammer or a ball impactor on the beam surface. This mechanical impact will introduce stress waves, which include dilatational (P-) wave, distortional (S-) wave, and Rayleigh (R-) wave. The IE method mainly utilizes $\mathrm{P}$-wave to determine the depth of the surface-opening crack because $\mathrm{P}$-wave results in a considerably larger displacement than $\mathrm{S}$ - and R-waves. When the P-wave propagates in the beam along the spherical wavefronts, it will be reflected by the boundary of the crack and then be propagated as diffracted wave. The TOF technology, which is based on detecting the arrival time of the P-wave, can be used to estimate the crack depth.

Figure 1 shows a schematic of the testing configuration for the estimation of the crack depth. Figure 2 presents the recorded waveforms demonstrating P-wave arrivals. If a surface-opening crack exists, then the shortest travel path of $\mathrm{P}$-wave generated by the mechanical impact starts from the impact point to the crack tip and then arrives at the sensor 2, which is illustrated by the dashed line in Fig. 1. The depth of the surface-opening crack $D$ can then be calculated according to [9] as follows:

$$
D=\sqrt{\left[\frac{\left(C_{P} \times \Delta t\right)^{2}+H_{1}{ }^{2}-H_{2}{ }^{2}}{2 \times C_{p} \times \Delta t}\right]^{2}-H_{1}{ }^{2}},
$$

where $H_{1}$ is the distance between the impact point and the crack, $\mathrm{H}_{2}$ represents the distance between the second sensor and the crack, $\mathrm{H}_{3}$ denotes the distance between the impact point and the first sensor, $C_{P}$ is the travel velocity of the $\mathrm{P}$-wave, and $\Delta t$ denotes the travel time for the P-wave from the start of the impact to the arrival of the P-wave at sensor 2.

Figure 2 shows that the time for data acquisition is earlier than the occurrence time of the mechanical impact $t_{0}$; meanwhile, $t_{0}$ cannot be read from the data acquisition system. However, $\Delta t$ can be calculated by the difference between the arrival times from the impact point to the first and second sensors. In Fig. 2, the upper part shows the waveform recorded by the sensor 1 , whereas the lower part is the waveform recorded by the sensor 2. $t_{1}$ and $t_{2}$ represent the time from the start of

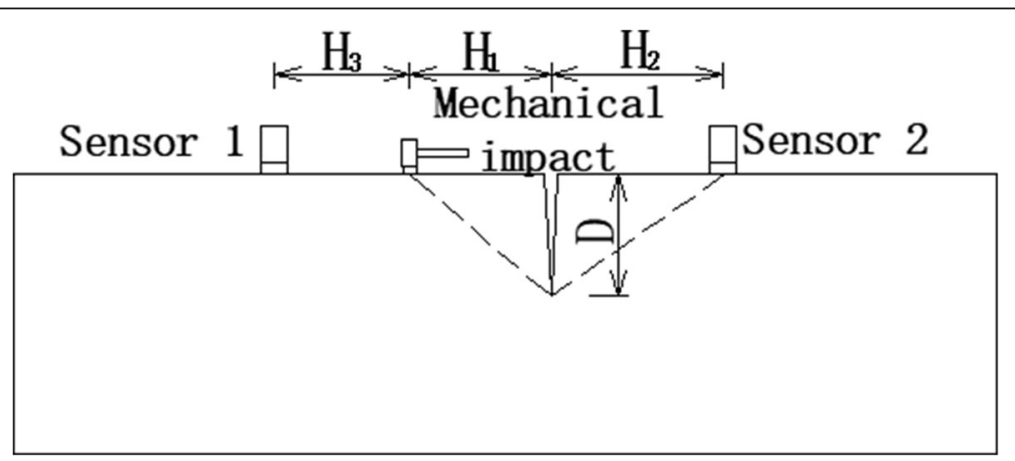

Fig. 1 Schematic of testing configuration for estimating the depth of the crack 


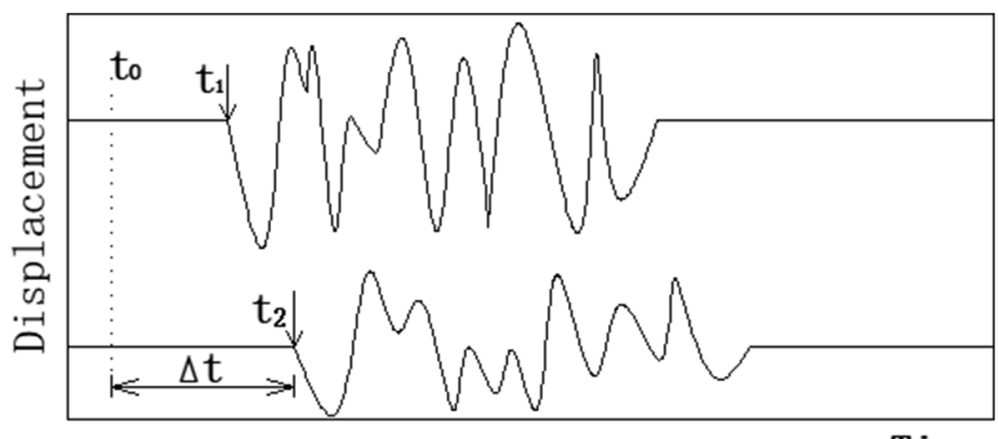

Time

Fig. 2 Typical recorded waveforms showing P-wave arrivals

data acquisition to the arrival of the P-wave at the first and second sensors, respectively. Consequently, the following relationships are obtained:

$$
t_{1}-t_{0}=H_{3} / C_{P} .
$$

Hence, $\Delta t=t_{2}-t_{0}$ can be further expressed as Eq. (3) in combination with Eq. (2), as shown as follows:

$$
\Delta_{t}=t_{2}-t_{1}+H_{3} / C_{P}
$$

Figure 3 shows that two sensors can be placed at the top of an intact concrete beam with a certain distance $L$ to determine the travel velocity of the P-wave. A mechanical impact is then exerted on the surface of the concrete beam. The travel velocity of P-wave can be determined as follows:

$$
C_{P}=L /\left(t_{2}^{\prime}-t_{1}^{\prime}\right)
$$

where $t_{1}^{\prime}$ and $t_{2}^{\prime}$ represent the time from the data acquisition to the arrival of $\mathrm{P}$-wave at the first and second sensors placed at the top of the intact concrete beam, respectively. Thus, the depth of the surface-opening crack can be estimated in combination with Eqs. (1), (3), and (4).

\subsection{Non-contact video-based method}

The non-contact video-based measurement system mainly comprises the following three components: a high-speed video camera with proper lens, the right target attached or labeled on the measured object, and a data acquisition and processing system. These components are shown in Fig. 4.

Cameras with various frame rates and resolutions are available. High-resolution cameras tend to have excellent resolution when tracking targets but may have low frame rates because they transfer a large amount of data per frame. Moreover, the choice of lens affects the size of the area viewed in the image. The size of this area is known as the field-of-view of the camera. Fitting different lens to the camera enables the measurement system to operate on objects from only a few millimeters in size up to several hundred meters.

The targets help the measurement system to track the object response. Five types of target pattern, namely speckles, blobs, dashes, concentric rings, and natural features of the object, are used to track the object response. Speckled patterns are ideal for precise measurement of displacement and strain and are produced by spraying with a light dusting of white spray paint followed by a light dusting of black paint. Blobs and dashes are suitable in cases where the strain and displacement are large. They do not usually need to be drawn precisely in

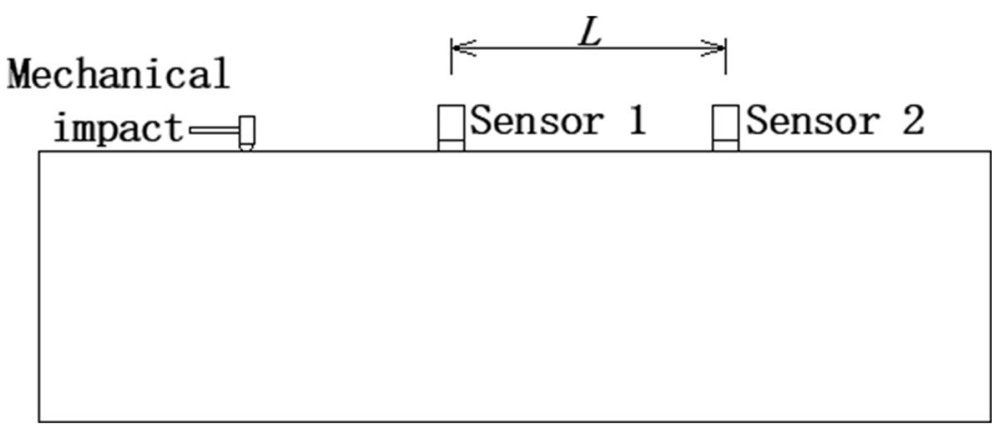

Fig. 3 Schematic of testing configuration for determining the velocity of P-wave 


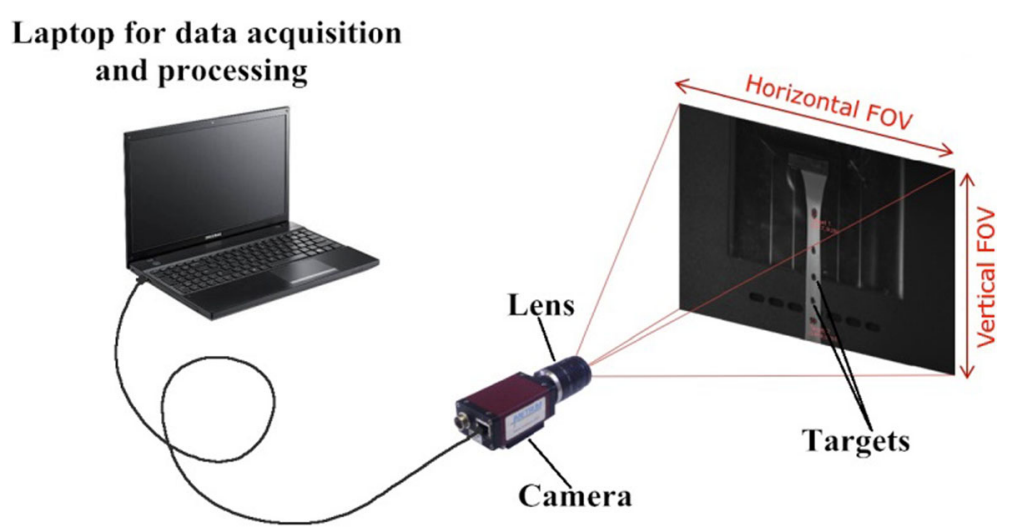

Fig. 4 Components of the non-contact video-based measurement system

a regular shape and can be drawn freehand. Concentric rings are ideal for measuring displacement on components and structures because they are circularly symmetric and will work well even with large amounts of rotation. An easy way to produce these targets is to generate them in a graphics program and then print them out onto sticky labels. Many objects have natural features or patterns that make them suitable as targets without the need for additional markings. Some materials have a natural texture (such as concrete or brick), whereas some components might have bolt or rivet heads that can be used as targets.

The measurement principle of the non-contact video-based measurement system can be illustrated as follows. After the targets are drawn onto the object surface, the pixels in the measured area on the object surface captured by the camera can be obtained and calculated by the data acquisition system. Once the object is applied to the external load, the object will be deformed, resulting in the change in the number of pixels in the measured area. If the difference in the number of pixels between different times in a certain direction is obtained, then the object displacement in this direction can be acquired by conversion through the data processing system. Meanwhile, if the change in the number of pixels between two different targets is obtained, then the deformation, rotation, or the strain value between the two targets can also be derived.

\section{Experiment}

\subsection{Specimen}

Two groups of specimens, which included six reinforced concrete beams, were casted and cured to conduct the experiment. Each group contained three concrete beams. These concrete beams, with length of $140 \mathrm{~cm}$, width of $9 \mathrm{~cm}$, and depth of $16 \mathrm{~cm}$, were reinforced with two identical reinforcing bars placed $2 \mathrm{~cm}$ above the bottom of the beams. Two identical spacer bars were also designed and placed $2 \mathrm{~cm}$ from the top surface of the beams. However, the spacer bars were disconnected in the middle zone of the beam with a length of $40 \mathrm{~cm}$. Stirrups were also designed with a spacing of $5 \mathrm{~cm}$. The diameters of the reinforcing bars in the first and second groups are $12 \mathrm{~mm}$ and $16 \mathrm{~mm}$, respectively, whereas the diameters of the spacer bar and stirrup were all $6 \mathrm{~mm}$. The reinforcing bars were designed with grade HRB335 with yield strength of $300 \mathrm{MPa}$ according to Chinese GB50010-2010 [18]. Meanwhile, the grade of the spacer bar and stirrups were HPB235 with yield strength of $210 \mathrm{MPa}$. The concrete mix followed the mixing proportion of cement:water:aggregate:sand $=1: 0.47: 3.39: 1.59$, resulting in the $\mathrm{C} 25$ concrete mix that exhibited compressive and tensile strength of $11.9 \mathrm{MPa}$ and $1.27 \mathrm{MPa}$, respectively. The Young's modulus of the reinforcing bar and the concrete mix were $200 \mathrm{GPa}$ and $28.0 \mathrm{GPa}$, respectively. The dimensions of the concrete beam are

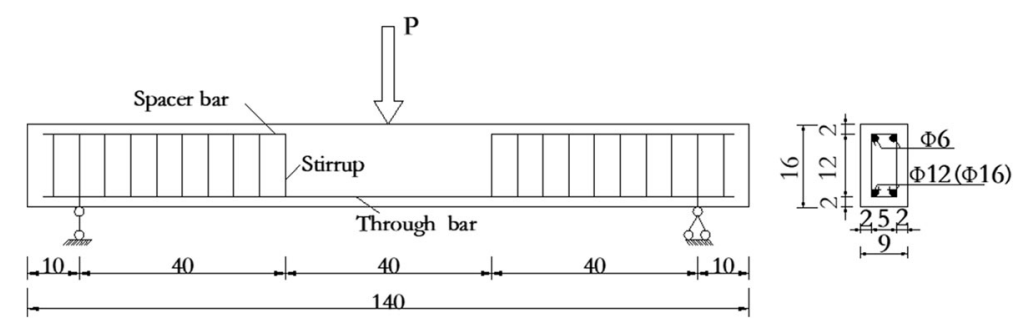

Fig. 5 Dimensions of test specimen and loading configuration 


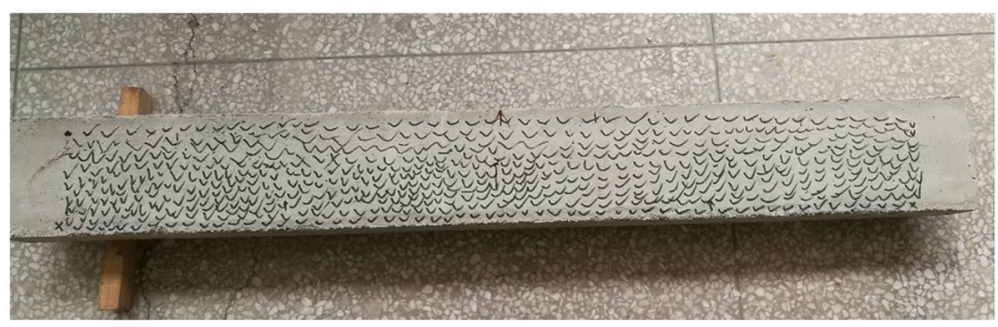

Fig. 6 Beam drawn with dash type targets

shown in Fig. 5. The specimens were labeled with the diameter of the reinforcing bar and the beam number (e.g., 12-1\# represents the first beam in which the diameter of the reinforcing bar is $12 \mathrm{~mm}$.).

As dashed targets are convenient to drawn freehand and any shape of the target can be identified by the camera, dash-type targets were used for the camera to capture the response of the concrete beam in this study. The dashes were hand-drawn with ticks using a black marker with a random distance between two nearby marks. A beam drawn with dashed targets is shown in Fig. 6.

\subsection{Loading}

The concrete beam specimens were loaded under a single-point loading to generate vertical surface-opening cracks, as shown in Fig. 5. From the figure, the tensile force initiated at the bottom of the beam; thus, the crack first occurred at the bottom of the beam and then developed toward the upper region. The load was applied at $100 \mathrm{~N} / \mathrm{s}$ and stopped when a visible crack occurred at the bottom of the beam. Under this single-point loading, several evenly distributed cracks may occur on the beam surface. However, only the most evident crack was selected to measure its depth using IE and non-contact video-based method in the experiment. Table 1 shows that the theoretical ultimate load when 12-1\#, 12-2\#, and $12-3 \#$ beams completely failed was $13.88 \mathrm{kN}$. For 16-1\#, 16-2\#, and 16-3\# beams, the theoretical ultimate load was $16.68 \mathrm{kN}$. In this experiment, the applied load

Table 1 Theoretical ultimate load and applied load when visible crack occurs for each specimen

\begin{tabular}{lcll}
\hline Specimen & $P_{\text {ultimate }}(\mathrm{kN})$ & $\mathrm{P}_{\text {applied }}(\mathrm{kN})$ & $\left(\mathrm{P}_{\text {applied }} / \mathrm{P}_{\text {ultimate }}\right)$ \\
\hline $12-1 \#$ & 13.88 & 5.24 & 37.75 \\
$12-2 \#$ & & 4.35 & 31.34 \\
$12-3 \#$ & & 4.82 & 34.73 \\
$16-1 \#$ & & 6.10 & 36.57 \\
$16-2 \#$ & 16.68 & 5.47 & 32.79 \\
$16-3 \#$ & & 7.29 & 43.71 \\
\hline
\end{tabular}

when the visible crack occurred for each beam was approximately $30-40 \%$ of their theoretical ultimate load. Besides, the applied load for each beam deviates each other much. This is because the applied load stops when a visible crack occurs. At this moment, several cracks may exist and the degree of cracking of each beam is uncontrolled. So the applied load of each beam has nothing to do with when the most visible crack occurs.

\subsection{Measurement apparatus}

The overview of the laboratory loading and measurement test is shown in Fig. 7. For the IE method, two capacitive sensors with a frequency range of $0-1000 \mathrm{~Hz}$ were adopted to raise the P-wave in the concrete beam. The sensors were attached on the top surface of the beam to determine the travel velocity of the P-wave in the concrete beam conveniently. However, the sensors were glued at the bottom surface of the concrete as the crack initiated at the bottom surface of the concrete. The dynamic signal testing and analysis system DH5925 was adopted to acquire and handle the vibration signals obtained by the sensors. This DH5925 system had eight channels to enable simultaneous acquisition and handling of eight vibration signals. An industrial camera with 5 million pixels, which can capture 120 frames per second, was adopted for the non-contact video-based

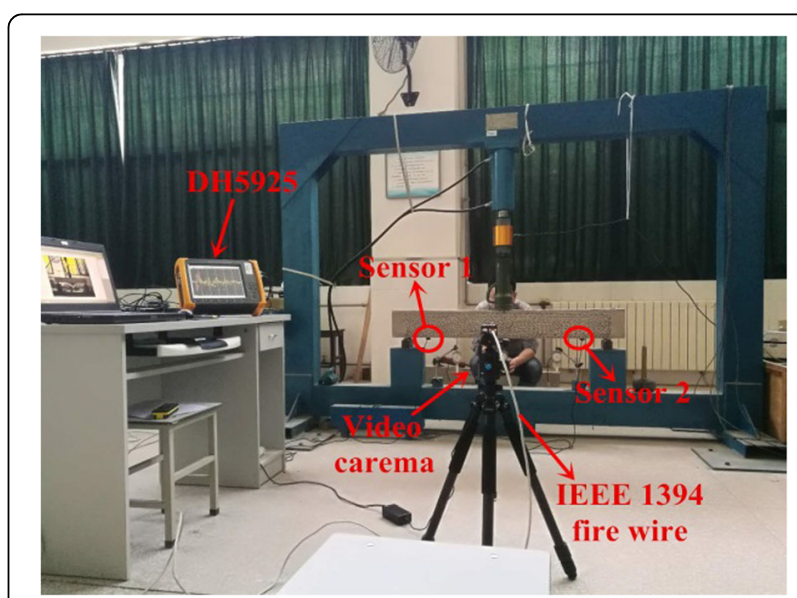

Fig. 7 Overview of the laboratory loading and measurement test 


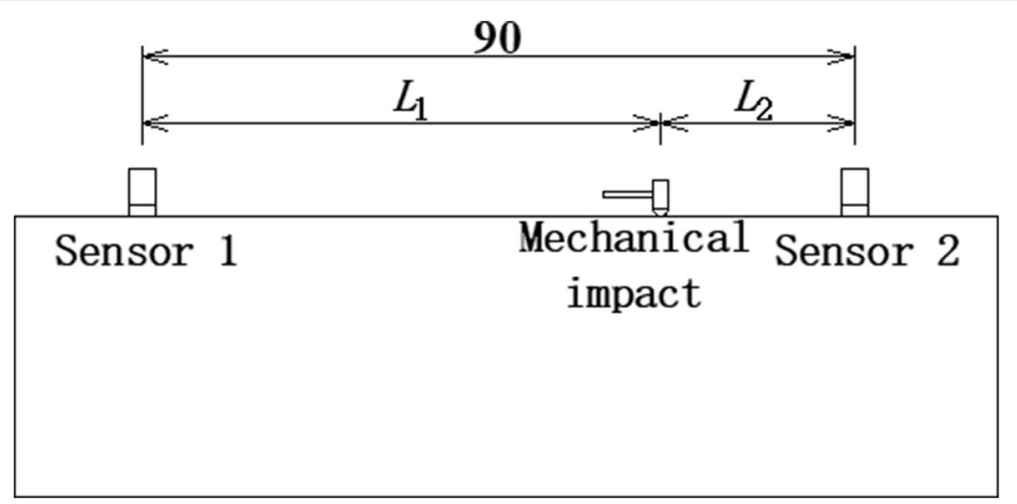

Fig. 8 Test configuration for the travel velocity of P-wave

method. The camera was placed right in front of the test beam with a proper distance to obtain a clear and full view of the beam. IEEE 1394 fire wire connected the camera and the laptop to satisfy a transmission speed of 400 Mbps. The specified software was installed on the laptop to help save the image files obtained from the camera for post-processing. To avoid the influence of light source on the test result, natural light without any other source of light was adopted in this study.

\subsection{Travel velocity of $\mathrm{P}$-wave}

Two beams with different through bars were tested to determine the travel velocity of P-wave in the concrete beams. The two sensors were attached on the top surface of the beam with a fixed distance of $90 \mathrm{~cm}$. By changing the impact position, the transmission distances from the impact position to the two sensors were correspondingly different, thereby causing varying arrival times of the P-wave at each sensor. Then, the TOF technique can be used to calculate the travel velocity of the P-wave. The difference of the distance between the impact position to the two sensors was designed as 30,50 , and $70 \mathrm{~cm}$ in this test. In this experiment, the test configuration for the travel velocity of the P-wave is shown in Fig. 8, and the test results are summarized in Table 2. The results showed that for concrete beams in groups 1

Table 2 Theoretical ultimate load and applied load when visible crack occurs for each specimen

\begin{tabular}{llllll}
\hline Specimen & $L_{1}(\mathrm{~cm})$ & $L_{2}(\mathrm{~cm})$ & $\Delta t(\mathrm{~s})$ & $C_{p}=\frac{\left|L_{1}-L_{2}\right|}{\Delta t}(\mathrm{~m} / \mathrm{s})$ & $\Delta C_{p}(\mathrm{~m} / \mathrm{s})$ \\
\hline Group 1 & 60 & 30 & 0.000085 & 3529.41 & 3529 \\
& 70 & 20 & 0.000142 & 3521.13 & \\
& 80 & 10 & 0.000196 & 3571.43 & \\
Group 2 & 60 & 30 & 0.000083 & 3614.46 & \\
& 70 & 20 & 0.000144 & 3472.22 & \\
& 80 & 10 & 0.000202 & 3465.35 & \\
\hline
\end{tabular}

and 2, the travel velocity of the P-wave demonstrated a slight difference and fluctuated around $3500 \mathrm{~m} / \mathrm{s}$. This finding indicated that the reinforcement ratio nearly had no influence on the travel velocity of the P-wave in the concrete beams. To this end, the average travel velocity of the P-wave in the two different groups of concrete beams, that is, $\Delta C_{p}=3529 \mathrm{~m} / \mathrm{s}$, was adopted to represent the travel velocity of the P-wave in the concrete beams in this experiment.

\section{Test results and discussions}

Given that the tensile strength and Young's modulus of the concrete were $1.27 \mathrm{MPa}$ and $28.0 \mathrm{GPa}$, respectively, the cracking strain of the concrete was easily calculated as $0.4536 \times 10^{-4}$ The spans and the cross sections of the beams in this study were all small. The maximum tensile strain under self-weight was $0.66 \times 10^{-5}$, which was small compared with the crack strain of the concrete. So the initial strain caused by self-weight of the beam was ignored when adopting non-contact video-based method. Based on this, if the strain of the concrete exceeded the cracking strain of $0.4536 \times 10^{-4}$, then a tensile crack would occur correspondingly. Through the non-contact video-based method, the strain map of the concrete would be drawn with different colors by the camera and the software. The strain of each point of the concrete beam could be obtained in the post-process. Thus, the tip and depth of the crack could be determined using the post-process software. For the 12-1\# beam, the most evident crack was located $3 \mathrm{~cm}$ left to the mid-span of the beam, and the crack depth measured by the non-contact video-based method was $6.04 \mathrm{~cm}$ (Fig. 9a). In the IE method, the distance values of $H_{1}, H_{2}$, and $H_{3}$ were set as $0.05,0.05$, and $0.10 \mathrm{~m}$, respectively, to measure the crack depth for the 12-1\# beam. The recorded waveforms showing the P-wave arrivals at each sensor are shown in Fig. 10a. The difference between the arrival times of the two sensors was 0.000017 s. By adopting 


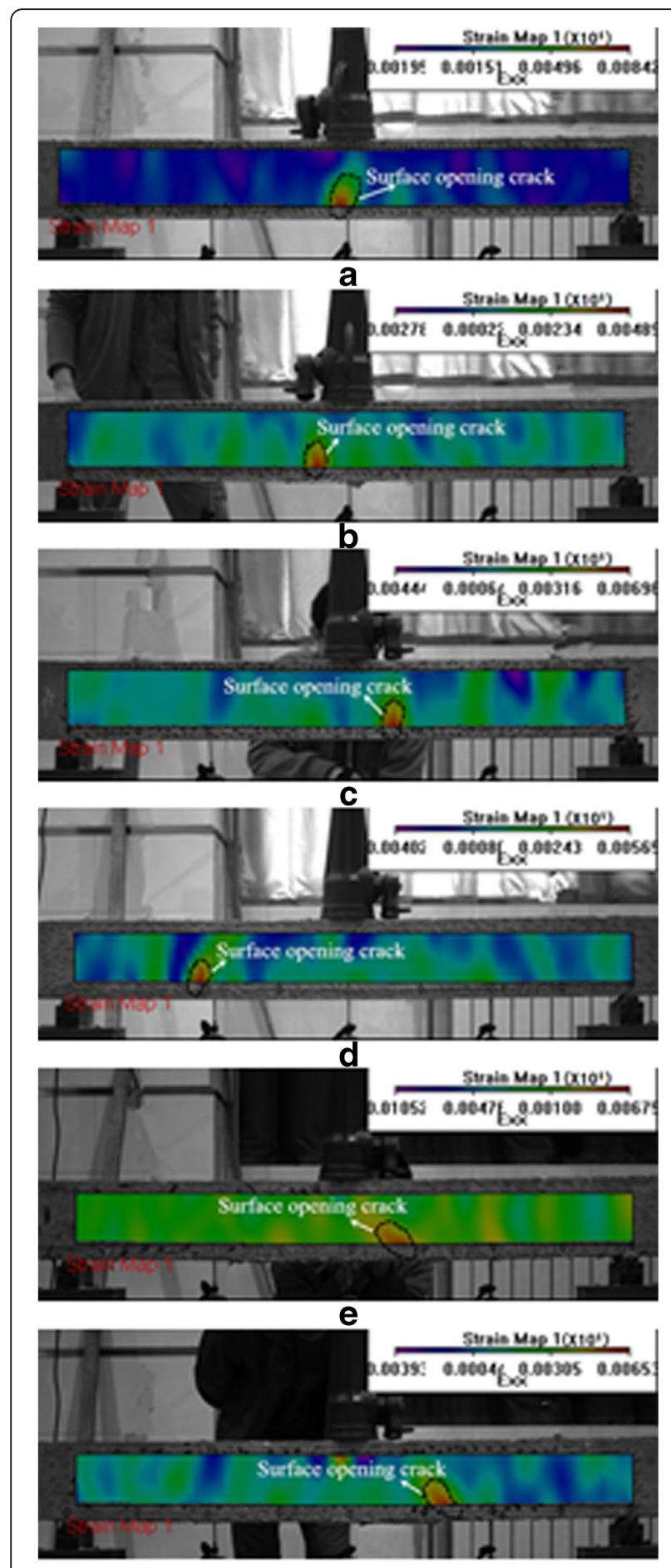

Fig. 9 View of non-contact video-based test result showing strain map of different beams: (a) 12-1\# beam; (b) 12-2\# beam; (c) 12-3\# beam; (d) 16-1\# beam; (e) 16-2\# beam; (f) 16-3\# beam

Eqs. (1) and (3), the crack depth determined by the IE method was calculated as $6.24 \mathrm{~cm}$. The most evident crack for the 12-2\# beam emerged at $6.4 \mathrm{~cm}$ left to the mid-span of the beam (Fig. 9b). The crack depth was estimated as $5.23 \mathrm{~cm}$ by the non-contact video-based method. By adopting the IE method, the distance values of $H_{1}, H_{2}$, and $H_{3}$ were set as $0.05,0.08$, and $0.12 \mathrm{~m}$, respectively, to measure the crack depth for the 12-2\# beam. The difference between the arrival times of the two sensors was $0.000015 \mathrm{~s}$ (Fig. 10b). Then, the crack depth for the 12-2\# beam was estimated as $5.61 \mathrm{~cm}$ according to Eqs. (1) and (3). For the 12-3\# beam, the most evident crack appeared at $13.7 \mathrm{~cm}$ right to the mid-span of the beam (Fig. 9c). The estimated crack depth by the non-contact video-based was obtained from the post-process software as $6.58 \mathrm{~cm}$. By placing the two sensors and the impact position with the distance values of $H_{1}, H_{2}$, and $H_{3}$ as $0.10,0.12$, and $0.15 \mathrm{~m}$, respectively, the time $\mathrm{P}$-wave traveled to sensor 2 was $0.000032 \mathrm{~s}$ later than its travel to sensor 1 (Fig. 10c). The crack depth for the 12-3\# beam was calculated as $7.18 \mathrm{~cm}$ using the IE method. The most evident crack for the 16-1\# beam emerged at $36.2 \mathrm{~cm}$ left to the mid-span of the beam (Fig. 9d). By adopting the non-contact video-based method, the crack depth was estimated as $5.92 \mathrm{~cm}$. By adopting the IE method, the difference between the arrival times of the two sensors of the $\mathrm{P}$-wave was $0.000014 \mathrm{~s}$ when the distance values of $H_{1}, H_{2}$, and $H_{3}$ were set as $0.10,0.05$, and $0.15 \mathrm{~m}$, respectively. The crack depth was then calculated as $6.22 \mathrm{~cm}$ according to Eqs. (1) and (3).

Figure 9 clearly shows that the cracks on $12-1 \#$, 12-2\#, 12-3\#, and 16-1\# beams were all vertical cracks. However, cracks that appeared on 16-2\# and 16-3\# beams were inclined cracks. The crack surface for the 16-2\# beam was located $10.5 \mathrm{~cm}$ right to the mid-span of the beam (Fig. 9e). Nonetheless, the crack surface for the 16-3\# beam emerged at $27.8 \mathrm{~cm}$ right to the mid-span of the beam (Fig. 9f). To test the depth of the inclined cracks by non-contact video-based method, the crack tip was also identified by preventing the strain of the concrete from exceeding the cracking strain of $0.4536 \times 10^{-4}$. Then, the depth of the inclined crack was the perpendicular distance between the crack tip and surface. According to the non-contact video-based method, the depths of most evident cracks for 16-2\# and 16-3\# beams were $6.71 \mathrm{~cm}$ and $6.24 \mathrm{~cm}$, respectively. When measuring the crack depth for the 16-2\# beam using the IE method, the distance values of $H_{1}, H_{2}$, and $H_{3}$ were set as $0.05,0.10$, and $0.15 \mathrm{~m}$, respectively. The difference in the arrival time for the $\mathrm{P}$-wave to the two sensors was $0.000020 \mathrm{~s}$ (Fig. 10e), and the crack depth was calculated as $7.88 \mathrm{~cm}$ according to Eqs. (1) and (3). Similarly, the distance values of $\mathrm{H}_{1}, \mathrm{H}_{2}$, and $\mathrm{H}_{3}$ for the 16-3\# beam were designed as $0.10,0.05$, and $0.12 \mathrm{~mm}$, respectively, and the difference in the arrival time for the P-wave to the two sensors was 0.000026 s (Fig. 10f). By adopting Eqs. (1) and (3), 


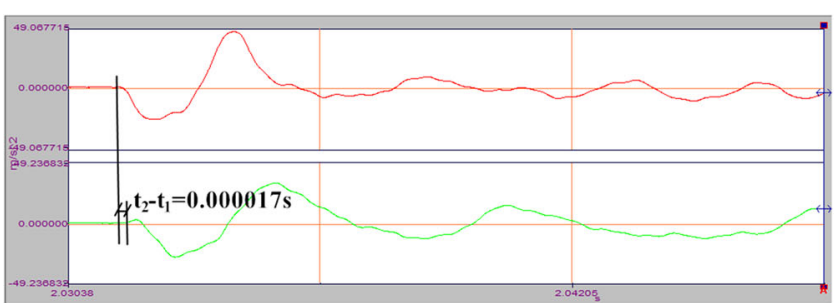

a

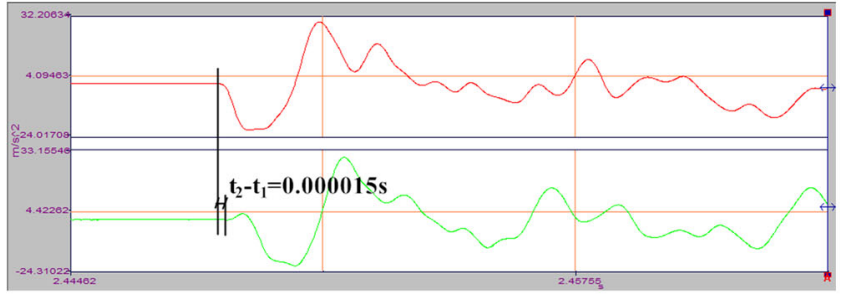

b

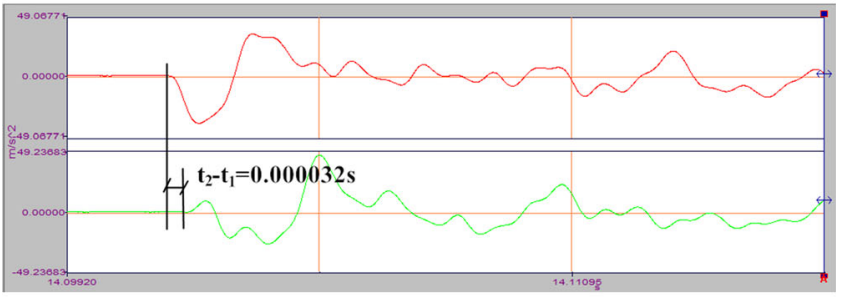

C

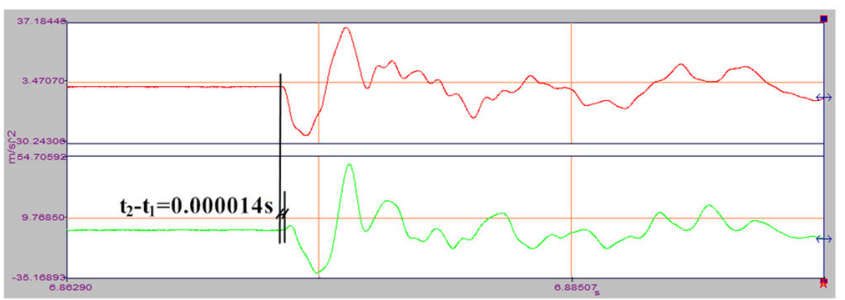

d

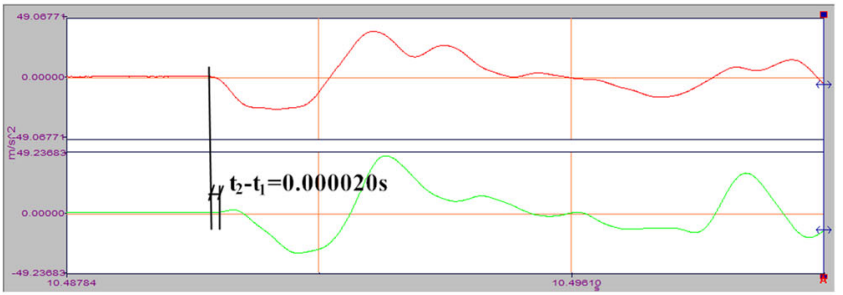

e

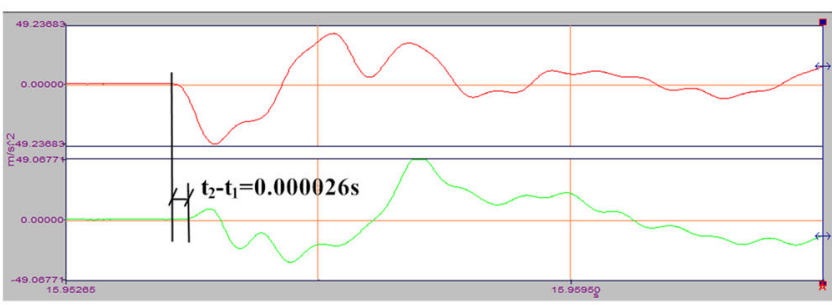

f

Fig. 10 Recorded waveforms showing P-wave arrivals: (a) 12-1\# beam; (b) 12-2\# beam; (c) 12-3\# beam; (d) 16-1\# beam; (e) 16-2\# beam; (f) 16-3\# beam 
Table 3 Comparison of depth measurements among different methods (unit: $\mathrm{cm}$ )

\begin{tabular}{llll}
\hline Specimen & $\begin{array}{l}\text { Visual } \\
\text { inspection }\end{array}$ & $\begin{array}{l}\text { Impact-echo } \\
\text { method }\end{array}$ & $\begin{array}{l}\text { Non-contact } \\
\text { video-based } \\
\text { method }\end{array}$ \\
\hline $12-1 \#$ & 5.95 & 6.24 & 6.04 \\
$12-2 \#$ & 5.02 & 5.61 & 5.23 \\
$12-3 \#$ & 6.34 & 7.18 & 6.58 \\
$16-1 \#$ & 5.78 & 6.22 & 5.92 \\
$16-2 \#$ & 6.45 & 7.88 & 6.71 \\
$16-3 \#$ & 5.90 & 7.26 & 6.24 \\
\hline
\end{tabular}

the crack depth for the 16-3\# beam was estimated as $7.26 \mathrm{~cm}$ using the IE method.

\subsection{Comparison among different methods}

The depth of each crack was also measured by visual inspection using a ruler, which read the scale from the tip to the top surface of the crack. Table 3 summarizes the crack depth of each specimen measured by the following three methods, namely IE method, non-contact video-based method, and visual inspection.

Table 3 shows that the IE method estimated the largest crack depth, followed by the non-contact video-based method. The crack depth was measured slightly smaller by visual inspection than that by the non-contact video-based method. Two reasons may explain why the IE method provided a larger crack depth estimation than those of the two other methods. First, the crack depth was not uniform in the cross-sectional area, wherein the crack depth was large inside the cross-section and small at the side surface of the cross-section. When adopting the IE method, the crack depth represented the depth inside the cross-section of the crack because the P-wave is a type of body wave rather than surface wave. Second, the concrete mixture was an unrealistic homogeneous material. Once defects existed, such as micro-crack or delamination near the crack tip, the travel distance of the P-wave increased, resulting in an overestimated crack depth. Moreover, the visual inspection measured a smaller crack depth than the non-contact video-based method. This finding could be attributed to inconspicuous micro-crack near the crack tip, which was difficult to observe by visual inspection. However, the micro-crack could be identified by the non-contact video-based method using the post-process software. Thus, the crack depth may be underestimated by the visual inspection.

On the basis of the preceding description, the measured cracks for specimens 16-2\# and 16-3\# were inclined cracks, whereas those for other specimens were vertical cracks. Table 3 shows that when adopting the IE method, specimens $16-1 \#$ and 16-2\# showed a larger deviation from the two other methods than the other specimens. This finding revealed that the IE method overestimated more the depth of the inclined crack than the vertical crack. This result could be attributed by the important angle between the crack and sensor 2 when measuring the depth of the inclined crack. A large angle implies a larger crack depth estimation [19].

For inclined cracks on 16-2\# and 16-3\# beams, the IE method can directly estimate the depth of the crack. When it comes to the length of inclined crack, the inclined angle of the crack $\theta$ is needed and the length can be calculated as $\mathrm{D} / \sin \theta$ indirectly. Besides, when a beam has already worked with a crack, the depth of the crack cannot be estimated using the non-contact video-based method. However, the change in the strain of the crack can be obtained by non-contact video-based method. Thus, change in the stiffness of the beam and the change in the depth of the crack can be estimated by the non-contact video-based method.

\section{Conclusions}

This study presents two methods, namely IE method and non-contact video-based method, for estimating the depth of surface-opening crack in concrete beams. Depths of vertical and inclined cracks are investigated. The estimated depth by the two methods is compared with visual inspection. The key conclusions drawn from this study on the surface-opening cracks are as follows.

1. The IE method estimates a considerably larger depth than the non-contact video-based method and visual inspection mainly because the crack depth is not uniform in the cross-sectional area and the depth inside the cross-section is larger than that at the side surface.

2. The non-contact video-based method estimates a slightly larger depth than that of the visual inspection. However, the difference in the crack depth estimated by the two methods is small because the non-contact video-based method can identify the unrecognizable micro-crack by visual inspection. However, the post-process of the non-contact video-based method requires expertise to identify the crack tip accurately.

3. When adopting the IE method, the depth of inclined crack is more overestimated than the vertical crack. This finding is strongly associated with the angle between the crack and sensor 2 .

4. The trajectory of the inclined crack in this study can be determined by the non-contact video-based method using the strain map. However, the IE method cannot achieve this goal, thus requiring further research. 


\section{Abbreviations}

IE: Impact-echo; TOF: Time-of-flight

\section{Acknowledgements}

The authors thank the editor and anonymous reviewers for their helpful comments and valuable suggestions.

\section{Funding}

Not applicable.

\section{Availability of data and materials}

Please contact the authors for data requests.

\section{Authors' contributions}

Sun did the experiments and finished the manuscript. All authors take part in the discussion of the work described in this paper. All authors read and approved the final manuscript.

\section{Competing interests}

The authors declare that they have no competing interests.

\section{Publisher's Note}

Springer Nature remains neutral with regard to jurisdictional claims in published maps and institutional affiliations.

Received: 17 September 2018 Accepted: 23 November 2018

Published online: 17 December 2018

\section{References}

1. H.B. Xie, W.J. Wu, Y.F. Wang, Life-time reliability based optimization of bridge maintenance strategy considering LCA and LCC. J. Clean. Prod. 176 36-45 (2018)

2. M. Seher, C.-W. In, J.-Y. Kim, et al., Numerical and experimental study of crack depth measurement in concrete using diffuse ultrasound. J. Nondestruct. Eval. 32, 81-92 (2013)

3. S.K.U. Rehman, Z. Ibrahim, S.A. Memon, et al., Nondestructive test methods for concrete bridges: a review. Constr. Build. Mater. 107, 58-86 (2016)

4. N.J. Carino, M. Sansalone, Flaw detection in concrete using the impact-echo method. Ndt. \& E. Int. 30(1), 263 (1997)

5. S.K. Verma, S.S. Bhadauria, S. Akhtar, Review of nondestructive testing methods for condition monitoring of concrete structures. J. Constr. Eng. 2013, 1-11 (2013)

6. C.U. Grosse, H.W. Reinhardt, R. Beutel, Application of impact-echo techniques for crack detection and crack parameter estimation in concrete. Biochim. Biophys. Acta 47, 417-422 (2005)

7. M.T. Liang, P.J. Su, Detection of the corrosion damage of rebar in concrete using impact-echo method. Cement. Concrete. Res. 31, 1427-1436 (2001)

8. N. Dawood, H. Marzouk, A. Hussein, et al., Nondestructive assessment of a Jetty bridge structure using impact-Echo and Shear-wave techniques. J. Bridg. Eng. 18, 801-809 (2013)

9. Y.C. Lin, W.C. Su, Use of stress waves for determining the depth of surfaceopening cracks in concrete structures. J. Mater. 93, 494-501 (1996)

10. M.J. Sansalone, J.M. Lin, W.B. Streett, Determining the depth of surfaceopening cracks using impact-generated stress waves and time-of-flight techniques. ACl Mater. J. 95, 168-177 (1998)

11. K. Arne, C.-W. In, J.-Y. Kim, et al., Nondestructive estimation of depth of surface opening cracks in concrete beams. AIP. Conf. Proc. 1581, 793-798 (2014)

12. E Çam, S Orhan, M Lüy. An analysis of cracked beam structure using impact echo method. Ndt \& E International. 38(5), 368-373 (2005)

13. D. Ribeiro, R. Calçada, J. Ferreira, et al., Non-contact measurement of the dynamic displacement of railway bridges using an advanced video-based system. Eng. Struct. 75, 164-180 (2014)

14. J.J. Lee, M. Shinozuka, A vision-based system for remote sensing of bridge displacement. Ndt. \&. E. Int. 39, 425-431 (2006)

15. A.M. Wahbeh, J.P. Caffrey, S.F. Masri, Direct measurement of displacements in vibrating structures through vision-based approaches. Emir. J. Eng. Res. 9, 105-110 (2004)

16. P. Qiao, W. Lestari, M.G. Shah, Dynamics-based damage detection of composite laminated beams using contact and noncontact measurement systems. J. Compos. Mater. 41, 1217-1252 (2007)
17. G. Busca, A. Cigada, P. Mazzoleni, et al., Vibration monitoring of multiple bridge points by means of a unique vision-based measuring system. Exp. Mech. 54, 255-271 (2014)

18. Chinese Code for Design of Concrete Structures (GB 50010-2010). Beijing, China. China Architecture \& Building Press (2010) (in Chinese)

19. D.S. Raghavendra, K. Sivasubramanian, A. Sivakumar, et al., Experimental evaluation of crack depth in concrete specimens using time-of-flight technique. J. Struct. Eng. 43, 311-318 (2016)

\section{Submit your manuscript to a SpringerOpen ${ }^{\circ}$ journal and benefit from:}

- Convenient online submission

- Rigorous peer review

- Open access: articles freely available online

- High visibility within the field

- Retaining the copyright to your article

Submit your next manuscript at $\boldsymbol{\nabla}$ springeropen.com 